\title{
Memória em desconstrução: da ditadura à pós-ditadura
}

Paloma Vidal

I.

Sob ditadura, o poder estatal se torna criminoso e se estende de tal forma, que todas as experiências cotidianas se vêem subitamente tomadas pelo medo. Como narrar isso? A maioria dos escritores argentinos se fez essa pergunta nos últimos anos da década de 1970. Como dar conta de uma realidade cindida entre o discurso oficial, reproduzido por grande parte da mídia, e uma série de outros relatos subterrâneos que testemunham uma violência tão excessiva que beira a irrealidade? Se os formalistas russos nos ensinaram que a literatura deve tornar estranho o familiar, desautomatizando nossa relação com a realidade, o que fazer quando o familiar se torna tão estranho que custa a distinguir real e irreal? Da confrontação com esse estranhamento radical surge boa parte dos textos escritos nessa época.

Rodolfo Enrique Fogwill - ou, simplesmente, Fogwill, como vem assinando seus livros há vários anos - publicou seu primeiro livro, uma coletânea de poemas intitulada El efecto de realidad, em 1979, com quase quarenta anos. No ano seguinte, foi a vez do livro de contos Mis muertos punk, que incluiu um de seus textos mais conhecidos, "Muchacha punk" ["Garota punk”]. Após a publicação desse livro, Fogwill passou a se dedicar à literatura, uma escolha guiada por um caráter agonístico que encontramos também em entrevistas e artigos, em que sustenta uma "resistência atávica à comunhão de idéias"*1. Essa persona pública é reconhecível, fragmentariamente, em muitos de seus personagens, figuras cínicas que questionam os lugares-comuns da cultura e da política argentinas das últimas décadas. Fogwill é um "santo inquisidor mortificante", como diz Horacio González, que tem como alvo "as roldanas escondidas que colocam em movimento as maquinarias caladas da vida. E, o que é ainda mais abalador, da história nacional recente"**

" González, Horacio. "La pregunta del agonista". Em: El ojo mocho, 1995: 52).

"(Fogwill, Rodolfo Enrique.

"Entrevista". Em: El ojo mocho, 1995: 16).

${ }^{1}$ Todas as traduções são de minha autoria, exceto quando a referência bibliográfica indicar uma edição em português. 
" (Terán, Oscar. "Tiempos de memoria". Em: Punto de vista, n. 68, 2000: 11.12).
Desde o final dos anos 1970, ele vem abrindo feridas por meio de seus contos, que, republicados em novas edições ${ }^{2}$, atualizam a memória de um passado incômodo. No texto intitulado “Tiempos de memoria”, Oscar Terán distingue dois tipos de memória: uma é "a tentativa de embalsamar os fatos do passado para construir um panteão reconciliado”; a outra "coloca-se a serviço da justiça" e "nos restitui um fio de sentido"* A memória que as narrativas de Fogwill produzem não cumpre nenhum desses dois objetivos: o de restituir e, muitos menos, o de reconciliar. Nela, não há nada dos "valores do humanismo" aos quais nos remete Terán para justificar a necessidade de recuperar e conservar o passado por meio de uma memória restituidora. Seu efeito é uma desconstrução dos sentidos fixados na memória coletiva, que torna o passado uma interrogação para o presente.

Com um currículo que inclui estudos de sociologia, medicina, letras, filosofia, matemática, inglês, francês, alemão, música, princípios de grego e latim, além de empregos de professor, publicitário, consultor de mercado, jornalista e empresário, Fogwill é uma figura controvertida no meio literário local, odiado por uns e cultuado por outros. Seus textos, pouco estudados na academia, exploram um realismo dos lugares, pessoas, comportamentos e marcas especificamente argentinos. Encontramos neles uma obsessão pelo detalhe, pelas descrições minuciosas de espaços, objetos, mecanismos, um saber técnico que ele faz questão de demonstrar todo o tempo; como desdobramentos disso, uma obsessão pelo cálculo de todo tipo, seja de tempo, de distância, de objetos, de dinheiro etc.; outra por horários e datas que situem com exatidão quando aconteceram as coisas; e uma última, e fundamental, por reproduzir a língua real, a fala de cada tribo, de cada classe, de cada geração, a língua argentina em suas modulações contemporâneas.

A leitura de suas entrevistas e artigos nos confronta com um pensamento que não faz nenhuma concessão, nem à direita

${ }^{2}$ Dois anos depois de Mis muertos punk, Fogwill publicou Música japonesa, com onze contos, dois dos quais já publicados no livro anterior. Em 1983, foi a vez de Ejércitos imaginarios, que traz três contos de Mis muertos punk. O livro Muchacha punk foi publicado pela primeira vez em 1992, com oito contos, dos quais apenas dois inéditos. Na edição de 1998, sobraram cinco contos da primeira e se acrescentou um novo, "Cantos de marineros en las pampas". Em Ejércitos imaginarios, Fogwill passou a datar seus contos, o que permite saber quando foram escritos, independentemente do ano de publicação do livro. 
nem à esquerda, um pensamento ágil e provocador, "que às vezes vai a uma velocidade que o autor não consegue reconhecer”* Esse mesmo impulso reflexivo move suas narrativas, guiadas pela vontade de ir além das capas superficiais da realidade, para saber como esta funciona subterraneamente, calculando suas rotas e desvios; pela vontade de entender os mecanismos do poder, denunciando-os e, ao mesmo tempo, afirmando cinicamente sua inevitabilidade. Costuma-se dizer que Fogwill escreve como escreve porque estudou sociologia, foi publicitário, consultor de mercado etc., como se a escrita fosse o efeito desses saberes, mas se pode pensar na existência de um impulso anterior que o teria levado a se dedicar a cada uma dessas atividades e que também moveria sua escrita. Só que, ao começar a escrever, é possível que Fogwill tenha chegado à conclusão de que, em certo sentido, a literatura é um saber mais verdadeiro, um saber sobre o não-saber, sobre a impossibilidade de dominar os mecanismos que regem a realidade, sejam eles sociais, culturais, políticos, naturais ou sexuais.

À pergunta de como narrar sob ditadura, Fogwill responde com um tipo de deslocamento que opera no limite entre o estranhamento e a familiaridade, movendo-se por zonas obscuras da nação, de onde emite alguns sinais para o seu tempo. Suas narrativas desafiam um aspecto fundamental do período ditatorial: se o discurso autoritário fez questão de obturar a todos, ou quase todos, os meios de comunicação, com o objetivo de criar um monólogo do qual a população deveria ser apenas receptáculo; e se, diante disso, por medo ou acomodação, muitos optaram por tentar esquecer o que estava acontecendo ou fingir que nada ocorria, os textos de Fogwill pretendem interferir nesse circuito fechado, deixando constantemente perguntas em aberto, que ecoarão por muitos anos depois de terminada a ditadura, voltando-se, por exemplo, para o passado, a fim de assinalar "fissuras mais profundas e anteriores na sociedade argentina”* .

A literatura de Fogwill assume a tarefa de apontar para uma nação subterrânea, que causa tanta estranheza à maior parte dos argentinos quanto uma moça punk. "Em dezembro de 1978, fiz amor com uma moça punk", lemos na primeira linha de Muchacha punk. “Três punks entraram no lugar, eu era o único não espanhol capaz de testemunhar que isso estava acontecendo, que eles não as haviam chamado, que eles não eram punks e que não havia ali outro punk além das três moças punks"*. Uma moça punk é uma figura estranha até mesmo
"(Fogwill, Rodolfo Enrique. "Entrevista". Ob. cit.: 22).

"(Sarlo, Beatriz. "Política, ideologia y figuración lite rária". Em: Ficción y polí. tica: la narrativa argentina durante el proceso militar. Buenos Aires: Alianza Es. túdio, 1987: 33).

"(Fogwill, Rodolfo Enrique Muchacha punk. Buenos Aires: Sudamericana, 1998: 53).

"(:59). 
"(: 60).

"(: 61).

* (: 65).

"(Fogwill, Rodolfo Enrique. "Sobre Muchacha punk". Disponível em http://www. literatura.org/Fogwill/fsob. much.html. Acesso em 16 de junho de 2005) numa pizzaria londrina. Por trás dessa estranheza, no entanto, o narrador descobrirá a familiaridade dos traços fisionômicos que aprecia nas mulheres: "essas peles delicadas, esses olhos transparentes, esses narizes de traços exatos, 'cinzelados' sob pálpebras sedosas e bem acima de lábios e gengivas e pontinhas da língua cujo carmim perfeito titila pelo mundo proclamando a beleza interior do corpo aristocrático"*. A moça punk seria uma perfeita aristocrata, se não fossem "aquelas atitudes punks e os detalhes punks, que luzia, punk, como se não estivesse nem aí, negligentemente punk"*.

Esse misto de familiaridade e estranheza se prolonga pelos diálogos entre o narrador e a moça, os quais, embora estejam em castelhano, mantêm a sintaxe do inglês, em uma espécie de tradução ao pé da letra. "Se eu vou a seu hotel, você terá que pagar a eles minha permanência”, lemos. "É não sentido afirmou e me convidou para ir a sua"*. A estratégia não nos deixa esquecer que quem escreve é um estrangeiro, alguém que está traduzindo essa experiência; um argentino que, ao olhar para fora da janela da pizzaria, tenta imaginar "o que estariam fazendo as poucas pessoas que, de vez em quando, produziam breves interrupções na constância daquela paisagem urbana vazia"; alguém que se pergunta "por que qualquer ser humano andando por essas ruas me parecia encobrir sempre um terrorista irlandês"*. "Por que será?", insiste o narrador. A resposta não vem e o leitor é quem se pergunta: o que faz um argentino em Londres com uma moça punk em uma noite gelada de 1978? Esse narrador que, no início do conto, anuncia que nos decepcionará: ele é ele aqui. O que faz Fogwill com uma moça punk?

"A narrativa vinha sobrecarregada de propósitos teóricos e abunda em sinais, anagramas, provocações ao estado policial da época e insídias a escritores da moda"*, explica o autor. Trata-se, segundo a concepção da função da arte enunciada pelo próprio texto, de "testemunhar a realidade". O que quer dizer testemunhar a realidade para Fogwill? Que realidade ele pretende testemunhar? Como entender o testemunho em um conto que fala de uma moça punk, nascida em uma família inglesa rica, que gasta sua mesada com os cuidados de uma falsa cicatriz na bochecha esquerda? Certamente, há um deslocamento em relação ao que se poderia esperar de um testemunho escrito por um argentino em 1978. A moça mora em um apartamento chiquérrimo em frente ao Hyde Park, com um sótão de mais de 
cem metros quadrados, no qual "dormiam milhares de garrafas de vinho”. De repente, a descrição desloca narrador e leitor para uma outra realidade, que surge como o negativo dessa que em que vive a moça punk:

Havia cheiro de especiarias no lugar. Calculei um estoque de alimentos suficiente para que uma família e seus amigos argentinos sitiados pudessem resistir ao assédio do invasor normando por seis luas, até a chegada dos exércitos libertadores do rei Charles, e ao avançar os ofensores, obrigando-nos a lançar nossas últimas reservas de bolas de granito com a catapulta da ameia oeste, apareceu outra vez minha princesinha punk.*

"Muchacha punk" é pontuado por imagens e comentários desse tipo, referências que não chegamos a captar inteiramente, mas que remetem a diversas formas de violência. $\mathrm{O}$ passado imperialista inglês percorre a narrativa como a outra cara dessa aristocracia a que pertence a moça punk. Pertence e não pertence, já que ela mesma é um ser deslocado.

O movimento punk surgiu na década de 1970 como uma forma de contestação à rígida hierarquização da sociedade inglesa. A renovação musical do punk rock, liderada pelo Sex Pistols, mistura-se à revolta com uma situação de tédio cultural e decadência social. "Antiapolíneo, oposto ao narcisismo comercial, grotesco, rasgado, [o punk] oferece um corpo em vias de deterioração, quase repugnante: os olhos injetados de sangue por overdose ou bebedeira, a pele avermelhada, uma cicatriz"*. No final da década, contudo, o movimento já tinha se tornado uma moda, uma forma de se vestir e de se pentear, e perdido a capacidade de chocar e abalar. "Muchacha punk", assim, refere-se, na figura dessa "princesinha punk" com sua cicatriz de mentira, à decadência de uma época cuja marca foi o espírito transgressor e contestatário.

$\mathrm{Na}$ Argentina, essa decadência é selada pela ditadura. Com ela, encerra-se um ciclo de utopia política iniciado nos anos 1960. "A vanguarda política nos anos 1960 e 1970, testemunha ainda, como um último alento arrebatado de história e de final, esse encontro de ousadia, de imprudência, que se confecciona a partir de uma subjetividade moderna pensante em direção ao emaranhado que se dá na escuridão do social”** Fogwill vai até Londres para falar desse tempo póstumo. Ou melhor, por viver nele, Fogwill não vai até Londres e "Muchacha punk" é uma viagem realizada na escrita para falar do que lhe impede de
" (Echavarren, Roberto. Arte andrógino: estilo versus moda en un siglo corto. Buenos Aires: Colihue, 1998: 89).

" (Casullo, Nicolas. Pensar entre épocas: memorias, sujetos y crítica intelec. tual. Buenos Aires: Vitral, 2004: 11). 
" (Fogwill, Rodolfo Enrique. Muchacha punk. Ob. cit: 74).

" (Sarlo, Beatriz. "Una alu cinación dispersa en ago nía". Em: Punto de vista, VII, n० 21, 1984: 1). estar em Londres em dezembro de 1978. "Eu jamais me deitei com uma moça punk”, confessa inesperadamente o narrador. "Pior: eu jamais vi moças punks, nem estive em Londres, nem me foram franqueadas as portas de residências tão ilustres. Posso prová-lo: desde março de $1976^{3}$, não voltei a fazer amor com outras pessoas"*. Esse deslocamento, que aqui lhe permite falar de um presente marcado pelo horror, assim como de um projeto utópico interrompido, será uma constante na narrativa de Fogwill, uma estratégia para falar da nação a partir de suas bordas.

\section{II.}

"Em uma mesa-redonda sobre literatura e testemunho da qual participei, o público, sobretudo os jovens, interrogou-nos sobre uma questão que poderia ser definida nos seguintes termos: como restabelecer uma continuidade entre as experiências dos últimos dez anos e o presente"** Assim Beatriz Sarlo começa um texto publicado alguns meses após o fim da ditadura. A recuperação da memória como possibilidade de entender o passado e atuar no presente é a grande questão desse momento. Trata-se de uma tarefa em que estão em jogo o questionamento dos destinos da nação e a reconstrução de uma subjetividade esfacelada pela violência. Recomeçar a pensar o futuro depois de muitos anos de silêncio, a não ser que se queira simular a possibilidade de uma tabula rasa, equivale a voltar atrás e buscar um sentido para as experiências vividas nos anos de ditadura. Isso, por sua vez, implica ir mais atrás ainda, aos anos anteriores a ela, às conturbadas décadas de 1960 e 1970, auge das lutas populares e da radicalização ideológica.

A literatura participa desse movimento em direção ao passado. Surgem, pouco a pouco, narrativas dispostas a revêlo, e nesse movimento são revisitadas aquelas que, como as de Fogwill, foram escritas sob ditadura. Que tipo de memória desse tempo esses textos produzem? Que respostas dão às perguntas da pós-ditadura: o que aconteceu? Como isso aconteceu? Como isso nos aconteceu? Se o papel de uma memória que procura apurar os fatos e responsabilizar os culpados é fundamental, não é essa a função de uma literatura como a de Fogwill, a qual aponta para certos furos da memória, para estranhezas excluídas por esta, evidenciando que a rememoração

\footnotetext{
${ }^{3}$ A ditadura militar argentina teve início no dia 24 de março de 1976.
} 
é um processo fundamentalmente inacabado, e que esse núcleo de incompreensão é o que nos permite continuar indagando sobre o passado. Textos como os de Fogwill, que durante a ditadura atravessaram o silêncio para se debruçar sobre uma realidade alienada pela censura, passam a funcionar como uma forma de testemunho à margem de uma função restituidora da memória.

A mídia ocupou lugar central no período de abertura, quando começaram a vir à luz os horrores cometidos pelo poder autoritário. No caso da Argentina, logo no início do governo de Raúl Alfonsín, ela se encarregou de acompanhar o processo de "revelação" dos acontecimentos até então "ocultos" da ditadura militar. A maioria das reportagens e programas de televisão que começaram a aparecer nessa época sobre as atrocidades do regime tinha teor sensacionalista e sustentava, como modo de explicação do que acontecera, o que se chamou de teoria dos dois demônios, segundo a qual haveria uma equivalência no grau de violência entre a repressão militar e a guerrilha da esquerda. Uma exceção foi o programa da Comisión Nacional sobre la Desaparición de Personas (Conadep), exibido em 1984, em que foram apresentados, em um tom muito mais sóbrio do que o habitual nesse momento, fragmentos de biografias de pessoas que foram vítimas da ditadura ${ }^{4}$.

Um ano depois, tanto os jornais quanto a televisão acompanharam o julgamento das juntas militares, tendo inclusive sido lançado um periódico, El Diario del Juicio, destinado a esse propósito. Segundo Claudia Feld, "nessa etapa da transição, a função da memória foi associada principalmente à noção de Justiça, em seus dois significados: provar a verdade e fazer com que o peso da lei recaísse sobre aqueles que a haviam transgredido"**. Era preciso saber exatamente o que acontecera e condenar os culpados. Em alguma medida, acreditava-se que, se esse processo fosse levado a cabo, seria possível tornar o horror um assunto do passado em uma nação reconciliada. A mídia refletia esse desejo e, enquanto duraram os julgamentos, não deixou de estar atenta a eles. Gradualmente, no entanto, o assunto saiu de pauta, até perder quase todo o interesse com as

\footnotetext{
${ }^{4}$ Sobre esse programa, afirma Beatriz Sarlo: "Imagino uma pergunta que Nunca más respondeu durante uma hora e meia: como falar da morte? Como pode um discurso sobre a morte ser escutado desde a perspectiva da vida? E ainda: como é possível suportar um discurso sobre a morte". Sarlo, Beatriz. "Una alucinación dispersa en agonia" (Ob. cit.: 2).
}

" (Feld, Claudia. "El rating de la memoria en la tele. visión argentina". Em: Ri. chard, Nelly (ed.). Políticas y estéticas de la memoria. Santiago de Chile: Cuarto Propio, 2000: 79). 
leis de "Punto Final", de 1986, e "Obediencia Debida" seguinte, e com o indulto aos militares condenados concedido por Carlos Menem em 1990.

O tema só voltaria à mídia em 1995, após Adolfo Francisco Scilingo, ex-oficial da Marinha, ter descrito, diante das câmeras, uma das práticas de extermínio mais abomináveis do regime militar: os vôos que lançavam ao mar corpos de presos políticos. "A 'memória' voltava a ter rating, mas a televisão, desta vez, havia modificado seu papel, bem como os relatos emitidos por ela haviam mudado de conteúdo. Desta vez, a televisão não se propôs a ser uma mera 'acompanhante' e 'difusora' de uma verdade produzida num espaço extratelevisivo (o âmbito da Justiça, por exemplo); ela mesma gerou o acontecimento"*, definido em torno da expectativa de "saber toda a verdade" sobre os crimes da ditadura. Essa mesma expectativa guiou o documentário sobre o centro de torturas da Escuela de Mecánica de la Armada (ESMA), exibido em agosto de 1998.

Mas em nenhum dos dois casos, como mostra Feld, a promessa de restituição da verdade se cumpriu. No primeiro, não se foi muito além da exibição do torturador, isto é, o crime ganhou um rosto, mas essa figura que passou a representá-lo não acrescentou nenhuma informação que já não fosse conhecida. Não revelou, como era de se esperar, quais foram suas vítimas e quem participou com ele das operações de desaparecimento. Ao contrário, apenas ratificou os dados conhecidos sobre o seqüestro e a execução de pessoas durante a ditadura, assim como a justificativa para tais atos, recorrendo ao argumento da "guerra anti-subversiva": "repito, não estou arrependido do que fiz, porque era uma guerra”.

Também no caso do documentário sobre a ESMA, o que se viu foi a reiteração de informações já conhecidas pelo público, só que transmitidas por alguém que esteve lá, um filho de desaparecido que nasceu nesse local. Ao contrário do que aconteceu nos julgamentos exibidos pela televisão em 1985, aqui já não se tratava mais do discurso da lei, mas sim do testemunho pessoal de um sobrevivente, utilizado para despertar

${ }^{5}$ A lei do "Punto Final" instaurou um prazo máximo de sessenta dias, a partir da data de sua promulgação, para instaurar processos penais contra envolvidos nos crimes da ditadura. Já a lei de “Obediencia Debida” terminou definitivamente com a possibilidade de processar qualquer militar que não tivesse cargo de maior responsabilidade durante a ditadura. Juntas, tornaram efetivo o projeto de auto-anistia que o poder militar não conseguiu institucionalizar antes de sua retirada do governo. 
emoções no espectador. Sem ir muito além do pathos da compaixão, o documentário fez questão, como indica Feld, de não se aprofundar na vida dos pais da testemunha, despolitizando desse modo a história que estava sendo narrada.

Assim, nesses dois exemplos, apela-se aos personagens de carne e osso, vítima ou algoz, como forma de criar um acontecimento midiático que, apesar da promessa de contar toda a verdade, não vai além de informações já conhecidas. A promessa não se cumpre e a memória que se constrói é reiterativa. Além disso, por serem acontecimentos midiáticos, não cumprem também, como os julgamentos que se seguiram ao fim da ditadura, o papel de fazer justiça, deixando em evidência, ao contrário, a impunidade dos culpados. "Talvez”, conclui Feld:

o que atente contra a memória sobre as políticas de desaparecimento de pessoas em nossos países não seja somente o silêncio e a mentira, mas também, em alguma medida, certo tipo de relato midiático que transforma o horror em matéria-prima para o rating e baseia seu poder de convocação em uma velha expectativa ainda insatisfeita: a de 'saber toda a verdade'.*

Há, por certo, outras formas de operar com a memória, o que evidentemente não equivale a negar a importância dos rituais públicos de restituição da verdade e de julgamento dos culpados. Sem a pretensão de contar toda a verdade, algumas narrativas deixam vir à tona lugares inexplorados na construção da memória comum. "La larga risa de todos estos años" ["A longa risada de todos esses anos"] é um dessas narrativas. O conto, datado de 1983, que abre Ejércitos imaginarios [Exércitos imaginários] e foi publicado posteriormente nas duas edições de Muchacha punk, põe em cena uma memória que chamarei de desconstrutiva. O que se desconstrói é a imagem de uma Argentina vitimada e unida no presente em torno da condenação dos atos assassinos da ditadura, uma Argentina que finge esquecer o consentimento silencioso sem o qual esses atos não teriam sido possíveis.

"Não éramos tão felizes", diz o narrador na primeira frase do texto, para, logo em seguida, acrescentar que, "se alguém me perguntasse se éramos felizes, diria que sim, que éramos felizes, e acredito que ela também diria que fomos muito felizes durante aqueles anos 75, 76, e grande parte do ano de 1978, depois do último verão"* . Desde esse primeiro parágrafo, o texto deixa no ar esta pergunta: o que é a felicidade? É possível
"(: 84).

\footnotetext{
"(Fogwill, Rodolfo Enrique. "La larga hisa de todos estos años". Em: Ejércitos imaginarios. Buenos Aires: Centro Editor de América Latina, 1983: 9)
} 
que alguém tenha sido feliz na Argentina nesses “anos 75, 76, e grande parte do ano de 1978"?

Talvez sim. Talvez fosse possível viver sua vida e ignorar a existência do mundo exterior. O conto se constrói em torno dessa indiferença ${ }^{6}$, criando um espaço isolado que se pauta nas atividades diárias e na relação amorosa dos dois protagonistas: uma prostituta, Franca, que três vezes por semana ronda pelo centro de Buenos Aires em busca de clientes, e o narrador, sobre o qual sabemos apenas que luta judô, fuma muito e quase nunca sai de casa, a não ser para dar aulas na faculdade. Ao mesmo tempo que seu desinteresse pelo mundo externo é quase absoluto, tem uma verdadeira fixação por sua amante. "Uma mulher. O que saberiam eles sobre o que é uma mulher? Eu sei. Sei que ela era uma mulher"* É no relacionamento fechado com Franca que parece residir a possibilidade de felicidade.

"Custa crer, mas as pessoas, mesmo nas coisas que fazem na intimidade, se parecem entre si”. As pessoas, os dias, tudo no conto vai sendo absorvido pelo olhar indiferente do narrador, um olhar que não estabelece diferenças e para o qual tudo é normal: é normal a vida que Franca leva, inclusive sua relação com oficiais, suboficiais, inspetores; é normal que, diante dos desaparecimentos, seja preciso "branquear" sua situação, isto é, "contar o que a gente pensava, o que sabia que pensavam ou faziam os outros e o que pensava que faziam, pensavam ou sabiam os outros"*; é normal também que isso não seja garantia de nada em um tempo em que "não se podia colocar a mão no fogo por ninguém”* . Todo o horror da ditadura está contido nesse trecho, que é seguido por um outro em que a indiferença se estende para o mundo à volta do narrador. "Acho que todos viram o que foi acontecendo durante aqueles anos", ele provoca. "Muitos dizem que só agora ficaram sabendo. Outros, mais decentes, dizem que sempre souberam, mas que só agora compreendem. Poucos querem reconhecer que sempre souberam e sempre entenderam"*. Uma pergunta deixada em suspenso, em um trecho anterior do conto, reproduz a justificativa que se tornou freqüente para a apatia dessa época: "Que outra coisa poderiam fazer?"**

\footnotetext{
${ }^{6}$ Segundo Fogwill, o conto seria uma "épica da indiferença” (citado por Reggiani, Federico. "La fama de las letras: el papel de la literatura en la patria de tres cuentos de Fogwill”. Em: Literatura argentina y nacionalismo: Gálvez, Fogwill, Saer, Aira. (La Plata: Universidad Nacional de la Plata: 1995: 74)..
} 
O narrador encerrará seu relato dizendo que tudo muda, enquanto o leitor se pergunta o que é que muda, se o que o conto mostra é o retorno do mesmo. Se, por exemplo, o lugar ocupado por Franca passa a ser ocupado por Claudia, também prostituta. Se as mesmas cenas de ciúme que aconteciam com a amante anterior se repetem com a nova e têm o mesmo desfecho. Se o narrador continua fazendo todas as tardes o que fez ao longo de todas as tardes de sua vida. Ora, o que muda é o dinheiro. A referência à impossibilidade de calcular quanto valia o dinheiro naquele período aparece diversas vezes no conto: "seriam vinte ou 25 mil pesos: uns cem dólares, quinhentos mil de agora. Como dizê-lo, se o valor do dinheiro muda mais do qualquer hábito das pessoas?”" . E em outro trecho: “não sei quanto valia o dinheiro então"* À circularidade e à imutabilidade da vida do narrador se opõe esse elemento que foge ao controle e que assinala que nada é o que parece. "As cifras são falsas", lemos. $\mathrm{O}$ dinheiro surge como um fator de instabilidade nesse tempo que, como o narrador quer nos fazer crer, teria transcorrido sem grandes alterações. Assinala, além disso, o ponto cego da ditadura, seu fundamento financeiro, isso que "ninguém lembra"*. Nessa referência, portanto, o conto antecipa a questão da década de 1990, quando a estabilidade monetária se torna a máscara da nação. Se aqui a instabilidade da moeda sinaliza as mudanças irreversíveis pelas quais a nação passou, na grande ficção nacional criada pelo governo de Menem, a estabilidade monetária pretende garantir o esquecimento delas.

Quase no fim da narrativa, lemos: "outra vez abriram-se as cicatrizes"*. Ao passo que a memória restituidora busca fechar as feridas, fazendo justiça, a memória desconstrutiva deixa as feridas expostas. A ferida que se expõe aqui é a nação degradada pelo horror e pelo consentimento. Degradada também pela hipocrisia dos que "agora pensam ou dizem pensar coisas diferentes [...], porque se tornou um hábito falar ou pensar diferente, como antes se tornara um hábito aparentar que não se sabia ou fazer crer que se sabia, mas que não se compreendia”* . $\mathrm{O}$ conto rompe com essa hipocrisia no mesmo ato em que rompe com a moral dos que "vivem fingindo, ocultando o que acontece atrás”, os vizinhos com "seus olhares indiferentes no elevador”, fingindo não saber das brigas entre a narradora e sua amante. Nesse momento, em que chegamos ao final do conto, desconstrói-se, diante dos nossos olhos, o que acabamos de ler: o narrador é uma narradora, e que o que acabamos de ler é uma 
história de amor entre duas mulheres. O texto ri do leitor, no mesmo ato em que ri "de um país, de uma cidade, de um restaurante e de suas mesas parecidas, em que todo mundo come menus idênticos ao nosso e tudo parece natural, ou real”**

Os livros de contos de Fogwill constituem uma longa narrativa que vem sendo escrita desde o final dos anos 1970. Cada volume é um objeto construído com pedaços de um volume anterior, aos quais se acrescentam novos pedaços, ao mesmo tempo que os antigos são renovados, em um processo de constante reescrita, de forma que a obra, como a memória, fique em aberto. Para Fogwill, o livro é um objeto passageiro, que reúne temporariamente a obra, até que a edição se esgote e suma, para dar lugar a um outro livro, que retomará algumas partes do anterior e abandonará outras. A errata, por sua vez, não é uma exceção, mas o método mesmo da escrita, como é também o método, sempre falho, da memória. Nas incessantes correções, o texto se assume fundamentalmente inacabado, um work in progress. Contrabalançando essa instabilidade, porém, Fogwill faz questão de datar seus textos, meio pelo qual situa o ato da escrita que inaugura o trabalho da memória. 
